\title{
Screen printable flexible BiTe-SbTe based composite thermoelectric materials on textiles for wearable applications
}

\author{
Z Cao, M.J. Tudor, R.N. Torah and S.P. Beeby, Member, IEEE
}

\begin{abstract}
This paper presents the optimization of a bismuth tellurium $\left(\mathrm{Bi}_{1.8} \mathrm{Te}_{3.2}\right)$ - antimony tellurium $\left(\mathrm{Sb}_{2} \mathrm{Te}_{3}\right)$ based thermoelectric generator (TEG) fabricated by screen printing technology on flexible polyimide (Kapton) and textile substrates. New formulations of screen printable thermoelectric pastes are presented with optimised composition, curing conditions and printing parameters. The modifications of the thermoelectric materials enable them to be successfully deposited on flexible textile substrates. The optimized values of resistivity of the BiTe and SbTe thick films on Kapton were $9.97 \times 10^{-3} \Omega \cdot \mathrm{cm}$ and $3.57 \times 10^{-3} \Omega \cdot \mathrm{cm}$ respectively. The measured figure of merit at room temperature were 0.135 and 0.095 for BiTe and SbTe thick films on Kapton respectively. The dimension of each printed thermoleg was $20 \mathrm{~mm} \times 2 \mathrm{~mm} \times 70.5 \mu \mathrm{m}$. For the TEG on Kapton, the printed assembly comprising 8 thermocouples was coiled up and generated a voltage of $26.6 \mathrm{mV}$ and a maximum power output of $455.4 \mathrm{nW}$ at a temperature difference of $20^{\circ} \mathrm{C}$. For a printed TEG on textile, the maximum power output reached 2 $\mu \mathrm{W}$ from the same temperature difference.
\end{abstract}

Index Terms- Energy harvesting, Flexible electronics, Textiles, Thermoelectric device.

\section{INTRODUCTION}

$\mathrm{T}$ HE research field of energy harvesting concerns the conversion of various ambient energy sources into electrical domain in order to power autonomous systems including sensors, processors and communications [1]. There is considerable interest in using energy harvesting techniques to power body worn medical devices where the power consumption can typically vary from $0.01-10 \mathrm{~mW}$ depending mainly on the signal transmission rate [2]. Potential energy harvesting sources in these applications include motion and body heat[3]. Thermoelectric generators (TEGs), provide a reliable conversion technique suitable for locations where the temperature difference between the human body and ambient can be exploited. Medical sensors used in an indoor health monitoring system are an ideal application scenario for TEGs because other techniques such as solar and motion harvesting

This paper was summited on $1^{\text {st }}$ December, 2015 for review. This work was supported by the EPSRC under the grant reference EP/I005323/1. We also thank Kai Yang and Yang Wei for their contributions. The data for this paper can be found at DOI:10.5258/SOTON/381933.

Z. Cao, M. J. Tudor, R. N. Torah and S. P. Beeby are from University of Southampton, Southampton, SO17 1BJ, U.K. (spb@ecs.soton.ac.uk). will suffer from low illumination levels and lack of movement of the patients[4].

A flexible textile TEG is an attractive approach since it would provide a conformable interface that maximizes skin contact area whilst remaining comfortable to the user. Conventional fabrication methods for miniature devices, e.g. chemical vapor deposition or sputtering [5][6], are not suited to the production of TEGs on large area flexible substrate. Furthermore, sufficient device thickness is difficult to achieve using traditional microfabrication methods. Given these considerations, a potential technology to fabricate large area TEGs is screen printing, which only involves the deposition of synthesized thermoelectric inks followed by a curing process. The process of screen printing is a low-cost, straightforward method for fabricating the devices and, once developed, the inks will be compatible with a wide range of other printing processes (e.g. gravure, roll to roll).

The printed planar thermocouples, shown in Fig. 1, are connected electrically in series and thermally in parallel. The performance of the printed thermoelectric materials defined by the figure of merit given by equation 1 .

$$
Z T=\left(\alpha^{2} / \rho \lambda\right) T
$$

where $\alpha$ is the Seebeck coefficient, $\rho$ is the electrical conductivity, $\lambda$ is the thermal conductivity and $T$ is the absolute temperature. The output of the printed TEG, i.e. the generated voltage $(\mathrm{V})$ and the maximum power output (Pmax) are calculated from Equation 2 and 3.

$$
\begin{aligned}
V & =n \cdot \alpha_{n p} \cdot \Delta T \\
P_{\max } & =\frac{\left(n \cdot \alpha_{n p} \cdot \Delta T\right)^{2}}{4 R}
\end{aligned}
$$

where $\mathrm{n}$ is the number of the thermocouples; anp the Seebeck coefficient of single $\mathrm{p}$ - $\mathrm{n}$ junction; $\Delta \mathrm{T}$ the temperature difference between the two ends of the thermocouples and $\mathrm{R}$ is the internal resistance of the TEGs.

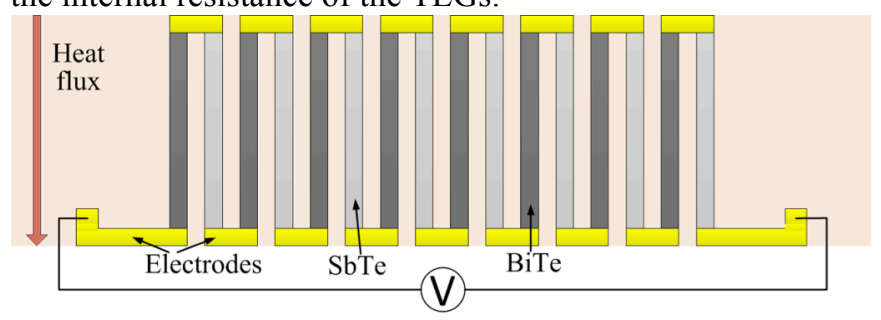

Fig. 1. Illustration of screen printed planar TEG connected with a voltmeter.

Organic polymer thermoelectric materials, such as 
poly(3,4-ethylenedioxythiophene) (PEDOT) also have the potential to be applied on flexible substrate [7]. However, the water-soluble polymer system is not particularly suited to screen printing technology due to lack of air stability and its power factor is not comparable with inorganic materials [8].

The performance of published screen printed thermoelectric materials is typically limited by high electrical resistivity [9][10], which limits the maximum power output of the devices (Equation 3). This work presents the optimization of a screen-printable thermoelectric paste and an investigation into the effects of bending and aging on the resistivity. In addition, most flexible TEGs reported were fabricated on polyimide substrates [11][12][13], while in this work, various textiles were investigated for use as the substrate and the first reported screen printed TEG on textile substrate for room temperature energy harvesting applications is presented.

\section{EXPERIMENTS}

\section{A. Material Preparation}

The actual stoichiometric ratio for BiTe and $\mathrm{SbTe}$ powers used in this experiment was $\mathrm{Bi}_{1.8} \mathrm{Te}_{3.2}$ and $\mathrm{Sb}_{2} \mathrm{Te}_{3}$, which contributed to the optimized figure of merit value. The $\mathrm{Bi}_{1.8} \mathrm{Te}_{3.2}$ and $\mathrm{Sb}_{2} \mathrm{Te}_{3}$ powders were obtained from Testbourne Ltd, with a particle size of 325 mesh (typically $\leq 10 \mu \mathrm{m}$ ) and a purity of $99.99 \%$. The $\mathrm{Bi}_{1.8} \mathrm{Te}_{3.2}$ and $\mathrm{Sb}_{2} \mathrm{Te}_{3}$ powders were used to formulate the n-type and p-type thermoelectric pastes respectively. The binder, which was epichlorohydrin polyglycol based epoxy (Dow Chemical), was used to adhere the thermoelectric materials onto the substrate and bind the adjacent particles together. The viscosity of the screen printable pastes was in the range of $9000 \mathrm{cP}-15000 \mathrm{cP}$, which was measured by Brookfield High Shear CAP-1000+ viscometer. A DAC 150 speed mixer (Synergy Devices Limited) was used to mix the paste to achieve a uniform particle distribution.

\section{B. Thick film properties characterization}

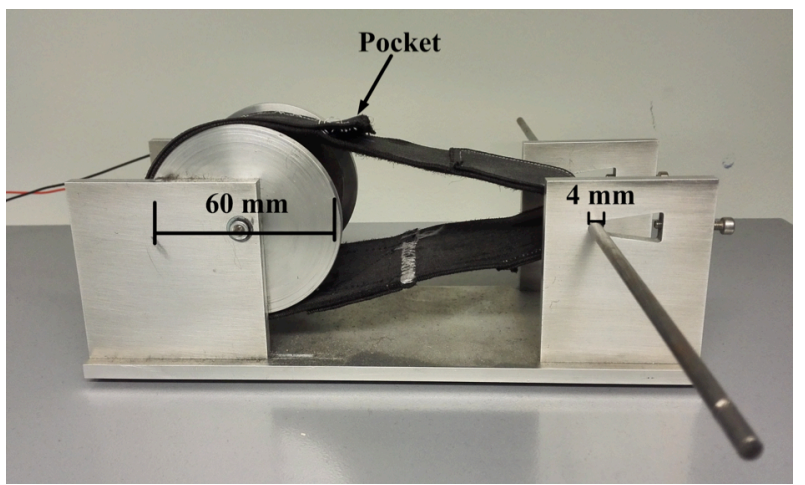

Fig. 2. The bending test setup, the diameter of big roller with motor is $60 \mathrm{~mm}$ while the small one is $4 \mathrm{~mm}$.

The samples used to test the resistivity and Seebeck coefficients of the films had dimensions of $1 \times 1 \mathrm{~cm} \times 70 \mu \mathrm{m}$. In this work, Hall Effect measurements were performed to test the transport properties and measure resistivity. This was done on a Ecopia HMS 3000 Hall Effect measurement system. The applied magnetic field was $0.37 \mathrm{~T}$ and the electrical current was $19 \mathrm{~mA}$. The Seebeck coefficients of the thermoelectric thick films were measured using a bespoke test rig [14]. In this bespoke rig, the hot end of a thermocouple was connected to a resistive heater while the cool end was put into an ice-water mixture. The temperature in the hot end can be adjusted by varying the current while the cool end was considered to be $0^{\circ} \mathrm{C}$. The thermal conductivity was measured by Netzsh LFA 447 Nanoflash. The effect of bending upon the sheet resistance was investigated by rolling the samples using the setup shown in Fig. 2. The printed film samples were placed in the pocket on the inside of the bend (in compression) and outside (in tension). The diameters for the big and small roller in figure 2 were $60 \mathrm{~mm}$ and $4 \mathrm{~mm}$ respectively. For the bending test, each sample was subject to 10 cycles and the sheet resistance before and after bending was measured. Sheet resistance was measured using a JANDEL RM3000 multi height probe machine. The Seebeck coefficient and resistivity were all measured in-plane.

\section{Device Fabrication and Performance Test}

The fabrication processes for the 4 TEGs presented in this work are illustrated in Fig. 3. One group of samples (TEGs I, III and IV) used SbTe as electrodes, while TEG II used copper as electrodes. The TEGs were all cured at $250{ }^{\circ} \mathrm{C}$ for 3 hours in $\mathrm{N} 2$ atmosphere to avoid oxidation during processing.
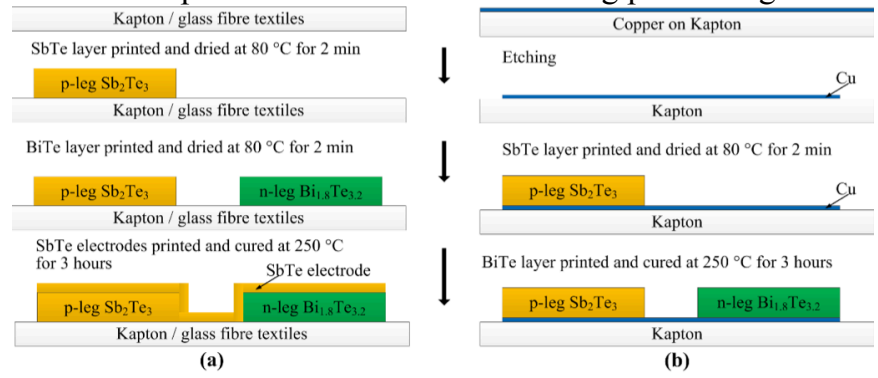

Fig. 3. The fabrication processes for TEGs using (a) $\mathrm{SbTe}$ as electrodes (TEGs I, III and IV) and (b) copper electrodes (TEG II).

The geometry of all the printed samples can be seen in Fig. 4 (a). For testing, the TEG strips were coiled up on a cylinder with a diameter of $28 \mathrm{~mm}$ (shown in Fig. 4 (b)). The top end of the TEG coil under test was placed in contact to the hot side of one Peltier and the bottom end of it was attached to the cold side of another Peltier. Thermal grease was applied to minimize the heat lost in air gaps. Hot and cold temperatures were measured at the interface between the coil and each Peltier.

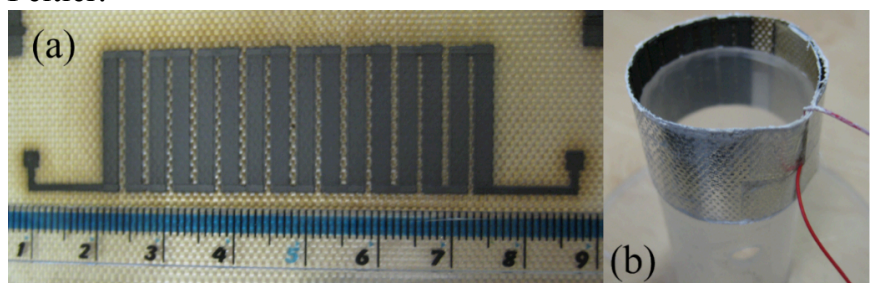

Fig. 4. Screen printed BiTe/SbTe thermocouples on glass fiber textile (a) and the coiled-up prototype (b). 


\section{OPTIMIZATION OF THE SCREEN PRINTED THERMOELECTRIC MATERIALS}

\section{A. Composition ratio optimization}

The pastes used in this investigation consist of two parts, the active particles and the binder system. The thermoelectric function is realized by BiTe and SbTe particles, while the flexibility of the film and the quality of adhesion to the substrate are provided by the polymer binder. As the polymer binder has much lower Seebeck coefficient and electrical conductivity compared with the active materials, the properties of the composite system are typically inferior to those of the bulk materials [12]. In order to minimize the electrical resistivity and maximize the thermoelectric properties, the highest possible ratio of active particles to binder should be used. However, sufficient polymer binder is required in order to achieve the desired film mechanical properties. Hence, there is a trade-off between the electrical and thermoelectric properties and the flexibility and adhesion of the film. Previous research has demonstrated that the electrical resistivity of printed BiTe thick films was around 10 times higher than SbTe thick film [10], which made reducing the resistance of the BiTe thick film the first priority.

Five different pastes with different BiTe ratio by weight were prepared. The percentages of BiTe particles investigated were $81 \%, 83.5 \%, 86 \%, 88.5 \%$ and $91 \%$. When the BiTe ratio was lower than $81 \%$ (or higher than $91 \%$ ), the viscosity of the pastes was too low (or too high) to be screen printed. Here, test samples were printed on Kapton and cured at $250{ }^{\circ} \mathrm{C}$ for 3 hours. All results were obtained from 30 measurements taken from 3 samples on each data point. The average Seebeck coefficient of the various compositions of BiTe thick films varied from $-134.4 \mu \mathrm{V} / \mathrm{K}$ to $-138.4 \mu \mathrm{V} / \mathrm{K}$ as shown in Fig. 5 . The variation range was within $3 \%$, which indicates the paste composition has negligible effect of the Seebeck coefficient.

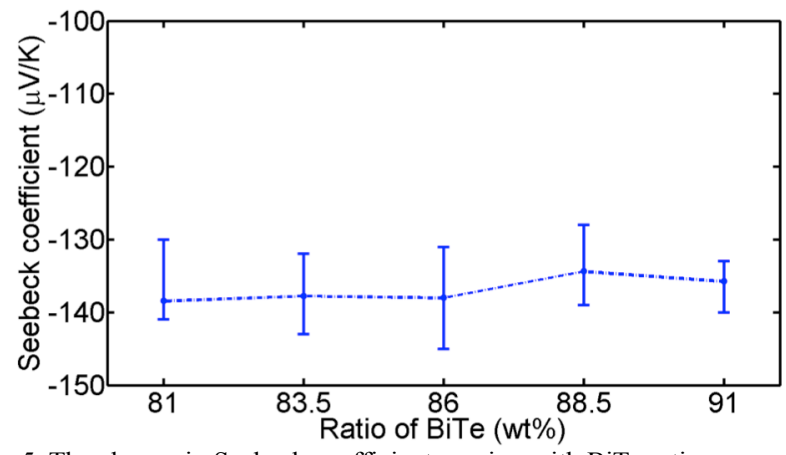

Fig. 5. The change in Seebeck coefficient varying with BiTe ratio.

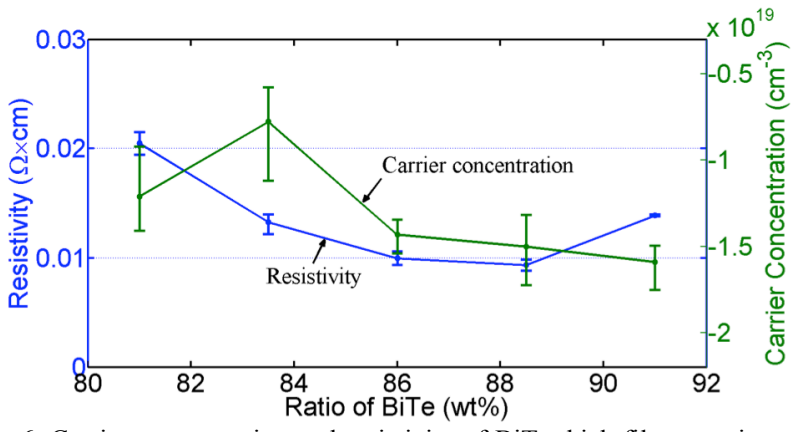

Fig. 6. Carrier concentration and resistivity of BiTe thick films varying with BiTe ratio

The resistivity and carrier concentration of the samples after curing are given in Fig. 6 . The resistivity decreases with the increasing ratio of BiTe up to $88.5 \%$, which gives a resistivity of $9.34 \times 10^{-3} \Omega \cdot \mathrm{cm}$. At $91 \%$ the resistivity was found to increase. According to $\sigma=\mathrm{nq} \mu$ ( $\mathrm{n}$ is carrier concentration, $\mathrm{q}$ is the charge, $\mu$ is the mobility), the conductivity is not only related to carrier concentration but also mobility. The poor distribution of the powders in high BiTe ratio composition pastes may decrease the mobility.

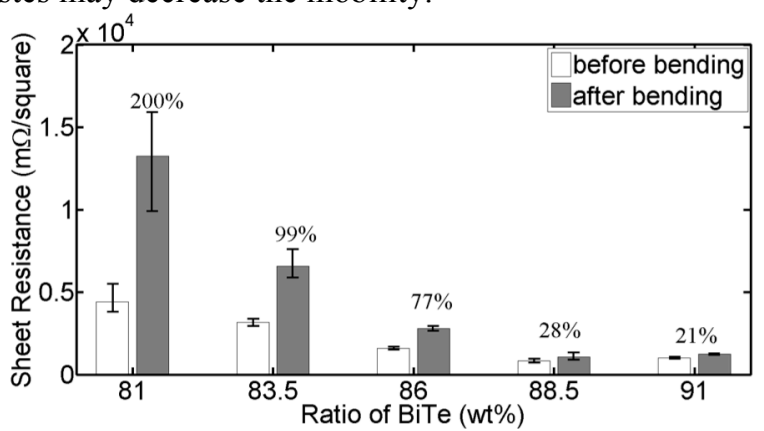

Fig. 7. The change in sheet resistance before and after bending test, varying with BiTe ratio.

The effect of bending upon the sheet resistance was investigated by rolling the samples using the setup shown in Fig. 2. The film was placed both on the inside of the bend (in compression) and outside (in tension). For the compressive case, all samples survived 10 bending cycles (see experimental section for details). The results are presented in Fig. 7 and these show that the compressive bending effect increases the sheet resistance of the BiTe samples but this effect reduces with increasing ratio of BiTe particles. The adhesion can be observed by bending the BiTe thick films with different ratios in tension around cylinders (shown in Fig. 8).

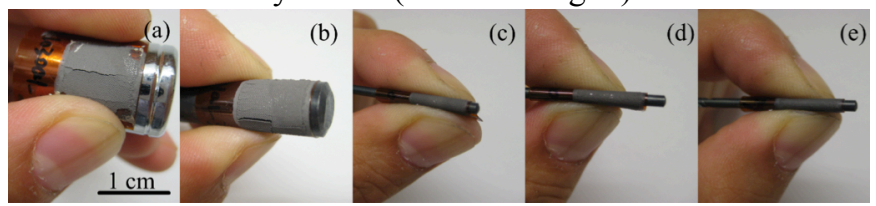

Fig. 8. The adhesion of BiTe thick film with different ratios: $91 \%$ samples cracked when bending at $15.8 \mathrm{~mm}$ diameter cylinder (a), 88.5\% samples cracked when bending at $8.3 \mathrm{~mm}$ diameter cylinder (b), no cracking observed for $86 \%$ (c), $83.5 \%$ (d) and $81 \%$ (e) samples when bending at $2 \mathrm{~mm}$ diameter cylinder.

From these results, the BiTe ratio of $86 \%$ was found to exhibit the optimum balance between flexibility, adhesion, electrical resistivity and thermoelectric performance. This formulation was therefore used in all the following 
experiments.

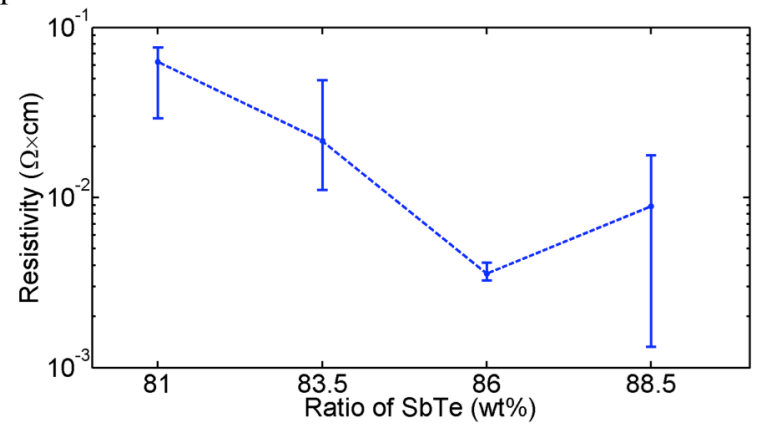

Fig. 9. The resistivity of SbTe thick films with different particle ratio.

For the $\mathrm{SbTe}$ films, composition ratios ranging from $81 \%$ and $88.5 \%$ were found to be screen printable. As shown in Fig. 9, the lowest resistivity is achieved with an active particle composition of $86 \%$. This composition was also found to survive the bending experiment with $2 \mathrm{~mm}$ radius in both tension and compression. Hence the optimum particle ratio for the $\mathrm{SbTe}$ pastes was also found to be $86 \%$.

\section{B. Curing temperature optimization}

The influence of curing temperature was evaluated by placing BiTe samples on a belt furnace at the following temperatures: $150{ }^{\circ} \mathrm{C}, 175{ }^{\circ} \mathrm{C}, 200{ }^{\circ} \mathrm{C}, 225{ }^{\circ} \mathrm{C}, 250{ }^{\circ} \mathrm{C}$ and $275^{\circ} \mathrm{C}$. The curing time for all samples was 3 hours and this was done in a nitrogen atmosphere to prevent oxidation. The adhesion of the BiTe thick films cured at $275^{\circ} \mathrm{C}$ was found to be poor and samples failed the bending test at $8 \mathrm{~mm}$, as shown in Fig. 10 (a) and a small piece of cured material peeled off after bending as shown in Fig. 10 (b).

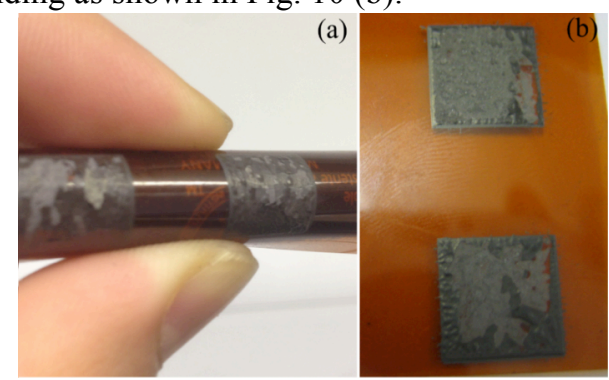

Fig. 10. The cracking of printed BiTe thick films cured at $275{ }^{\circ} \mathrm{C}$ when bending (a) and the damaged surface after bending (b) on $8 \mathrm{~mm}$ diameter cylinder
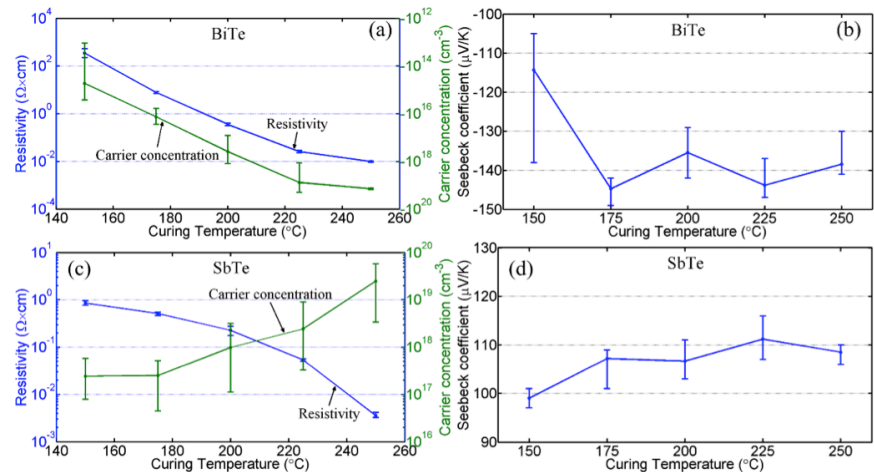

Fig. 11. The carrier concentration, electrical resistivity and Seebeck coefficient change with curing temperature for BiTe thick films ((a), (b)) and SbTe thick films ((c), (d)).

Fig. 11 shows the carrier concentration, electrical resistivity and Seebeck coefficient of the screen printed BiTe and SbTe thick films cured at different temperatures. The absolute carrier concentration was found to increase and the resistivity decrease dramatically with increasing curing temperature for both BiTe and SbTe materials. The Seebeck coefficient increased initially with curing temperature for both materials but BiTe remained constant and the SbTe showed only a limited increase beyond $175^{\circ} \mathrm{C}$. Given the relative importance of the printed film resistivity on TEG performance, the optimised curing condition was found to be $250{ }^{\circ} \mathrm{C}$ for 3 hours.

The SEM images in Fig. 12 indicated that the morphology change of the thick films cured from low to high temperatures. As the curing temperature increased from $150{ }^{\circ} \mathrm{C}$ to $250{ }^{\circ} \mathrm{C}$, There were more voids appeared in the thick films. This could be explained by the burning out of the polymer binders. When cured at $150{ }^{\circ} \mathrm{C}$, the spaces between adjacent BiTe particles were fully occupied by the polymer binder. The polymer binder is required to hold the particles together and onto substrate, and to form a flexible printed thick film.
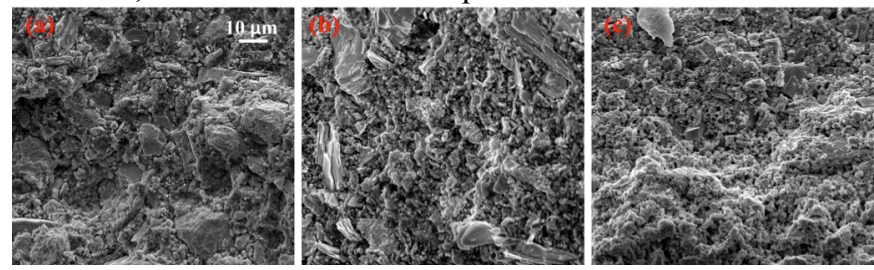

Fig. 12. The cross section SEM images of BiTe thick films cured at $150{ }^{\circ} \mathrm{C}$ (a), $200{ }^{\circ} \mathrm{C}$ (b) and $250{ }^{\circ} \mathrm{C}$ (c).

Previous work identified the issue of increasing electrical resistivity of printed BiTe and SbTe thick films after curing with time. In particular, the resistivity of BiTe was found to increase by around $100 \%$ after 50 days [10]. This paper presents pastes with reduced resistivity of both film materials and also reduced rates of oxidation over time, which slows down the increase in resistivity. Fig. 13 shows the change in average resistivity of the BiTe thick films. The initial resistivity of $9.97 \times 10^{-3} \Omega \cdot \mathrm{cm}$ compares very favorably to the previous BiTe paste $\left(1.8 \times 10^{-1} \Omega \cdot \mathrm{cm}\right)$. The increase in BiTe resistivity was also found to be only $6 \%$ after 50 days, compared with $100 \%$ increase of resistivity for BiTe films in previous work [10]. For the SbTe thick films, the new paste formulation reduced the initial resistivity from $1.76 \times 10^{-2}$ $\Omega \cdot \mathrm{cm}$ to $3.6 \times 10^{-3} \Omega \cdot \mathrm{cm}$ and the increase in resistivity fell from $17 \%$ to $8 \%$ after 50 days.
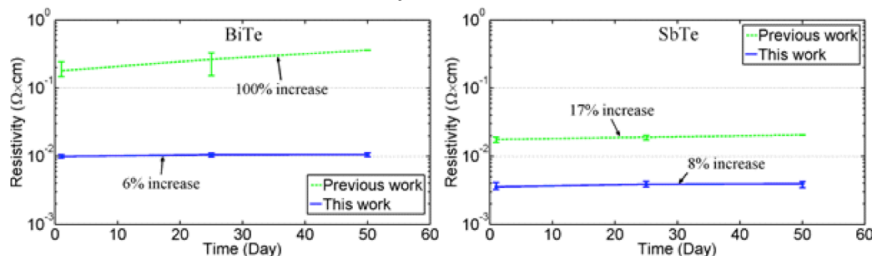

Fig. 13. The change in printed thick films electrical resistivity over 50 days compared with previous work [10]. 
TABLE I

SEEBECK COEFFICIENT, ELECTRICAL RESISTIVITY AND THERMAL CONDUCTIVITY FOR SCREEN PRINTED BITE/SBTE THICK FILMS AND BULK MATERIALS

\begin{tabular}{|c|c|c|c|c|c|}
\hline Material & $\alpha(\mu \mathrm{V} / \mathrm{K})$ & $\rho(\Omega \cdot \mathrm{cm})$ & $\begin{array}{c}\lambda \\
(\mathrm{W} /(\mathrm{m} \cdot \\
\mathrm{K}))\end{array}$ & $\begin{array}{l}\text { Power factor } \\
\left(\mu \mathrm{W} \cdot \mathrm{K}^{-2} \mathrm{~cm}^{-1}\right)\end{array}$ & $\begin{array}{c}\mathrm{ZT} \\
(\mathrm{T}=300 \\
\mathrm{K})\end{array}$ \\
\hline $\begin{array}{l}\mathrm{Bi}_{1.8} \mathrm{Te}_{3.2} \\
\text { Thick } \\
\text { film }\end{array}$ & -138.4 & $9.97 \times 10^{-3}$ & 0.426 & 1.92 & 0.135 \\
\hline $\begin{array}{l}\mathrm{Sb}_{2} \mathrm{Te}_{3} \\
\text { Thick } \\
\text { film }\end{array}$ & 108.5 & $3.6 \times 10^{-3}$ & 1.036 & 3.27 & 0.095 \\
\hline $\begin{array}{l}\text { Bulk } \\
\text { n-Bi }{ }_{2} \mathrm{Te}_{3} \\
{[15]}\end{array}$ & -227 & $\begin{array}{l}1.4- \\
3.8 \times 10^{-3}\end{array}$ & $1.5-2.5$ & $13.6-36.8$ & $\begin{array}{l}0.163- \\
0.736\end{array}$ \\
\hline $\begin{array}{l}\text { Bulk } \\
\mathrm{Sb}_{2} \mathrm{Te}_{3} \\
{[15]}\end{array}$ & 110 & $\begin{array}{l}2.5- \\
6 \times 10^{-4}\end{array}$ & $2.8-7.3$ & $20.2-48.4$ & $\begin{array}{l}0.083- \\
0.519\end{array}$ \\
\hline
\end{tabular}

The parameters used to calculate the figure of merit $\mathrm{ZT}$ are summarised in table I. The power factor of the printed films was around 10 times lower than for bulk materials, which is due to the relatively low Seebeck coefficient and electrical conductivity of the printed films. However, the lower thermal conductivity of the polymer binder benefits the figures of merit, which are of the same order as the bulk materials [15]. These results are also of the same order as the reported ZT for PEDOT of 0.25 [7] and a power factor of $9.47 \mu \mathrm{Wm}^{-1} \mathrm{~K}^{-2}$ PEDOT:PSS [8].

\section{THERMOELECTRIC THICK FILMS ON TEXTILE SUBSTRATE}

The previous results obtained on Kapton substrates have demonstrated the suitability of printed BiTe and SbTe films for the fabrication of flexible TEGs. The next step taken was to investigate the transfer of the printed materials and associated processes onto a textile substrate. A range of textiles were investigated and these are summarized in Table II. This includes a standard polyester/cotton $(65 \% / 35 \%)$ which is a common fabric used in clothing and is particularly challenging given the maximum processing temperature of $180^{\circ} \mathrm{C}$. The inherent surface roughness and pilosity of textiles also presents a significant challenge. Textiles can be pre-coated with a smooth film or a printed polyurethane waterproof interface layer has been developed in our research group for planarising the textile surface [16]. The curing temperature limitation of the polyester cotton means the films resistivity will be high (see Fig. 11), leading to poor thermoelectric performance. Therefore glass based textiles capable of withstanding higher processing temperatures were also investigated. These textiles were sufficiently smooth to allow printing directly on their surfaces.

The actual resistivity of the BiTe and $\mathrm{SbTe}$ films on the polyester cotton fabric were measured after curing at $150{ }^{\circ} \mathrm{C}$ and $175{ }^{\circ} \mathrm{C}$. The resistivity of the BiTe was $247 \Omega \cdot \mathrm{cm}$ and $23.5 \Omega \cdot \mathrm{cm}$ and for the SbTe films $7.6 \Omega \cdot \mathrm{cm}$ and $0.7 \Omega \cdot \mathrm{cm}$ when cured at $150{ }^{\circ} \mathrm{C}$ and $175{ }^{\circ} \mathrm{C}$ respectively. Whilst the resistivity values are marginally lower than the values measured on Kapton when cured at these temperatures, they remain too high and it is not possible to achieve adequate TEG performance on the polyester cotton fabric.
TABLE II

SUMMARIZATION OF THE TEXTILE PROPERTIES APPLIED IN THIS RESEARCH

\begin{tabular}{|c|c|c|c|c|}
\hline & $\begin{array}{c}\text { Ma } \\
\text { nufact-ur } \\
\text { er }\end{array}$ & Substrates & Material description & $\begin{array}{l}\text { Maximum } \\
\text { temperature }\end{array}$ \\
\hline (a) & Klopman & $\begin{array}{l}\text { Polyester / } \\
\text { cotton } \\
(65 \% / 35 \%)\end{array}$ & $\begin{array}{l}\text { Polyester / cotton with } \\
\text { polyurethane interface } \\
{[14]}\end{array}$ & $180^{\circ} \mathrm{C}$ \\
\hline (b) & Valmiera & $\begin{array}{l}\text { Valmiera } \\
1032 / 9682\end{array}$ & $\begin{array}{l}\text { plain woven glass } \\
\text { textile }\end{array}$ & $600^{\circ} \mathrm{C}$ \\
\hline (c) & Valmiera & $\begin{array}{l}\text { Valmiera } \\
440-\mathrm{AL}\end{array}$ & $\begin{array}{l}\text { four shaft satin woven } \\
\text { glass textile }\end{array}$ & $600^{\circ} \mathrm{C}$ \\
\hline (d) & ATEX & $\begin{array}{l}\text { ATEX } \\
3000\end{array}$ & $\begin{array}{l}\text { treated silicone coved } \\
\text { glass textile }\end{array}$ & $200^{\circ} \mathrm{C}$ \\
\hline (e) & ATEX & $\begin{array}{l}\text { ATEX } \\
3200-2-s p\end{array}$ & $\begin{array}{l}\text { polyurethane coved } \\
\text { glass textile }\end{array}$ & $260^{\circ} \mathrm{C}$ \\
\hline (f) & $\begin{array}{l}\text { PAR } \\
\text { Group }\end{array}$ & $\begin{array}{l}\text { PAR } \\
\text { GC409SG }\end{array}$ & $\begin{array}{l}\text { silicone coved glass } \\
\text { textile }\end{array}$ & $250^{\circ} \mathrm{C}$ \\
\hline (g) & $\begin{array}{l}\text { PAR } \\
\text { Group }\end{array}$ & PAR GC16 & $\begin{array}{l}\text { PTFE coated glass } \\
\text { textile }\end{array}$ & $260^{\circ} \mathrm{C}$ \\
\hline (h) & ATEX & $\begin{array}{l}\text { ATEX } \\
03321-2-W \\
\text { N }\end{array}$ & $\begin{array}{l}\text { Neoprene coated glass } \\
\text { textile }\end{array}$ & $260^{\circ} \mathrm{C}$ \\
\hline
\end{tabular}

The bending and adhesion of the BiTe films was then evaluated on the textiles summarised in table 2 and the results are shown in Fig. 14. The films on the glass textile substrates were cured at $250{ }^{\circ} \mathrm{C}$ in order to reduce resistivity. Among the selected glass based textiles, those coated with silicone and PTFE demonstrated poor adhesion to the BiTe thick films which readily cracked and peeled off (see Fig. 14 (d), (f) and (g)). The uncoated glass textiles (Fig. 14 (b) and (c)) and glass textiles coated with polyurethane and neoprene (Fig. 14 (e) and (h)) all showed adequate flexibility and adhesion and were therefore evaluated in subsequent experiments.

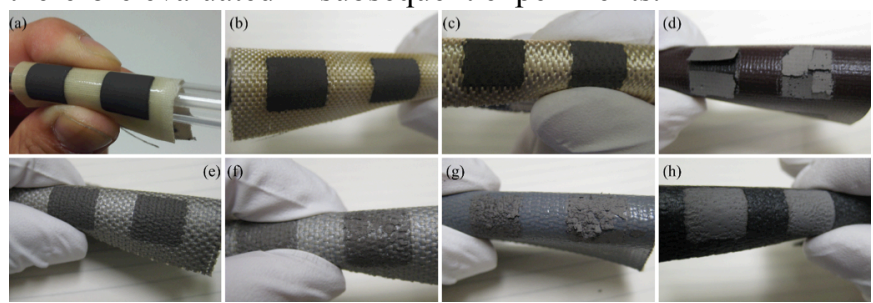

Fig. 14. Screen printed BiTe thick film samples on various substrates, (a): polyester/cotton with polyurethane interface [14]; (b): Valmiera 1032/9682; (c): Valmiera 440-AL; (d): ATEX 3000; (e): ATEX 3200-2-sp; (f): PAR GC409SG; (g): PAR GC16; (h): ATEX 03321-2-WN

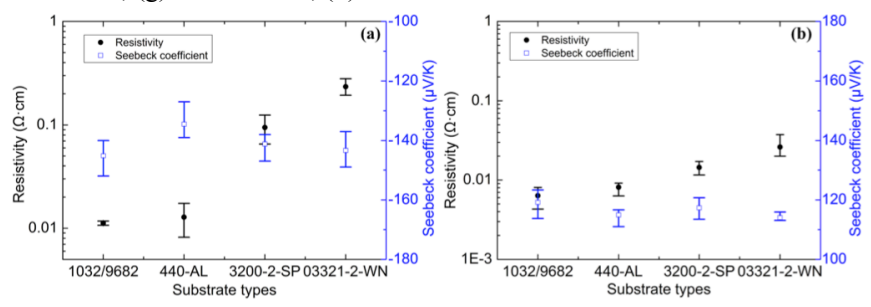

Fig. 15. Electrical resistivity and Seebeck coefficient of BiTe (a) and SbTe (b) thick films on selected glass fabrics substrates cured at $250^{\circ} \mathrm{C}$.

Fig. 15 shows the resistivity and Seebeck coefficients of the BiTe and SbTe thick films on the 4 selected glass textiles. The variation of resistivity on different textile substrates is much higher than the variation of the Seebeck coefficient.

For both BiTe and SbTe thick films, the uncoated glass textiles (Valmiera 1032/9628 and Valmiera 440-AL) demonstrated the lowest resistivity and sufficient Seebeck coefficients and therefore these were used to fabricate full TEGs. 


\section{THERMOELECTRIC PERFORMANCE OF TEXTILE AND KAPTON TEGS}

Glass textiles, Valmiera 1032/9628 and Valmiera 440-AL, and Kapton were used to investigate the thermoelectric device performance of printed TEGs. Four different TEG versions were printed. TEG I was printed on a Kapton substrate with SbTe interconnections between adjacent thermocouples. TEG II was also printed on Kapton but used thin film copper patterned using a lift off process as the thermocouple interconnections. TEGs III and IV were the textile TEGs printed on the Valmiera 1032/9628 and Valmiera 440-AL glass fiber textiles respectively with $\mathrm{SbTe}$ interconnections between adjacent thermocouples. The geometry for each thermoleg was $20 \times 2 \mathrm{~mm}$ and each TEG consists of 8 thermocouples. The average thermocouples thickness for TEGs I, II, III and IV were $70.5 \mu \mathrm{m}, 122.2 \mu \mathrm{m}, 173.6 \mu \mathrm{m}$ and $255.6 \mu \mathrm{m}$ respectively. The textile TEGs required a thicker thermoelectric film in order to overcome the surface roughness.

Fig. 16 shows the measured output voltage as a function of temperature difference. In the $\Delta \mathrm{T}$ range from $0{ }^{\circ} \mathrm{C}$ to $80{ }^{\circ} \mathrm{C}$, the output voltage increases linearly with temperature difference, indicating constant Seebeck coefficients. The Seebeck coefficients of these 4 samples ranges from 163.1 $\mu \mathrm{V} / \mathrm{K}$ to $229.3 \mu \mathrm{V} / \mathrm{K}$.

Fig. 17 shows the power output as a function of the load resistance for these 4 samples. TEG III had the highest Seebeck coefficient and the lowest internal resistance (144 $\Omega$ ) of the 4 samples. Whilst the resistivity of the thermoelectric films on textile substrates was of the same order as the samples on Kapton, the lower internal resistance is due to the increased thickness of the thermocouples in TEG III. For temperature gradient of $20^{\circ} \mathrm{C}$, TEG III delivered the highest power output of $2.3 \mu \mathrm{W}$. The thickness of thermocouples in TEG IV was too large and this resulted a large increase in resistance when bent into a coil. Full results for the coiled TEGs are given in table III.

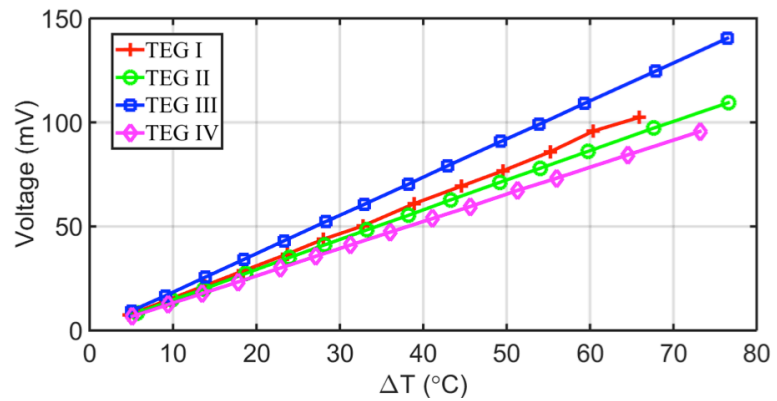

Fig. 16. The open circuit voltage vs. temperature difference for TEGs on Kapton and textile substrates.

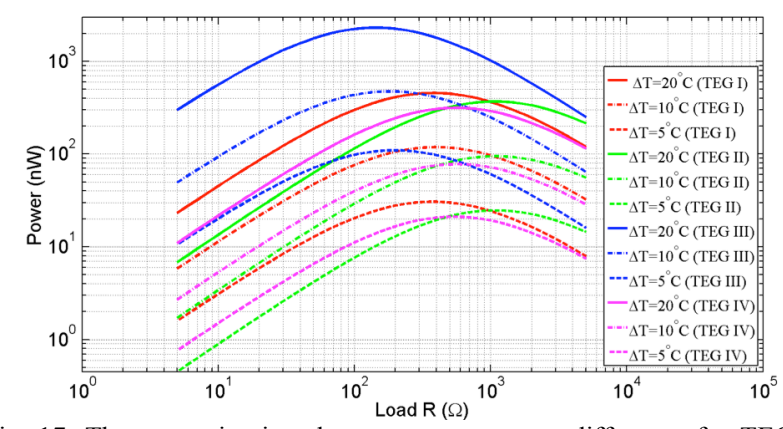

Fig. 17. The open circuit voltage vs. temperature difference for TEGs on Kapton and textile substrates.

\section{TABLE III}

THE SEEBECK COEFFICIENT OF SINGLE THERMOCOUPLE, INTERNAL RESISTANCE (WHEN COILED-UP) OF 8 THERMOCOUPLES AND MAXIMUM POWER OUTPUT $\left(\mathrm{P}_{\text {MAX }}\right)$ OF 8 THERMOCOUPLES FOR VARIOUS TEGS SAMPLES

\begin{tabular}{|l|l|l|l|l|}
\hline & TEG I & TEG II & $\begin{array}{c}\text { TEG } \\
\text { III }\end{array}$ & $\begin{array}{c}\text { TEG } \\
\text { IV }\end{array}$ \\
\hline Seebeck coeffic $\alpha_{\mathrm{np}}(\mu \mathrm{V} / \mathrm{K})$ & 165.0 & 248.8 & 227.7 & 166.5 \\
\hline Internal resistance $\mathrm{R}(\Omega \cdot)$ & 383 & 1074 & 144 & 563 \\
\hline $\mathrm{P}_{\max }(\mathrm{nW})\left(\Delta \mathrm{T}=20^{\circ} \mathrm{C}\right)$ & 455 & 369 & 2304 & 315 \\
\hline $\mathrm{P}_{\max }(\mathrm{nW})\left(\Delta \mathrm{T}=10^{\circ} \mathrm{C}\right)$ & 119 & 95 & 474 & 78 \\
\hline $\mathrm{P}_{\max }(\mathrm{nW})\left(\Delta \mathrm{T}=5^{\circ} \mathrm{C}\right)$ & 31 & 25 & 110 & 21 \\
\hline
\end{tabular}

The TEG with copper electrodes (TEG II) demonstrated a lower Seebeck coefficient and the highest internal resistance which resulted in less power output than the TEG with SbTe electrodes (TEG I). Hence, the copper electrode on Kapton architecture is not suitable for screen printed planar TEGs.

\section{CONCLUSION}

In summary, this work presents an optimized thermoelectric paste system for screen printed TEGs. Screen printing offers a low cost, batch fabrication approach and the materials demonstrated could also be used on higher volume roll to roll printing processes. The figure of merits at room temperature for BiTe and $\mathrm{SbTe}$ were found to be 0.135 and 0.095 respectively, which are close to the values of bulk materials. Among the three parameters which determine the figure of merit, electrical resistivity is the most critical and should be the subject of further investigation in order to improve the performance of printed TEGs.

This work also demonstrated the printing of TEGs on textiles which is motivated by the potential for use in wearable applications. The temperature constraints imposed by standard polyester cotton fabrics, however, greatly reduce the performance of the printed thermoelectric films. TEGs were successfully printed on high temperature textiles and this produced a power output of $2.3 \mu \mathrm{W}$ from a temperature gradient of $20^{\circ} \mathrm{C}$, which is sufficient for some low power long-term cardiac monitoring processors [17].

By varying the composition percentage, the curing temperature and different textile substrates, the resistivity of the printed thermoelectric thick films had a much higher variation than the Seebeck coefficient which remained reasonably constant. The thick films on uncoated textiles demonstrated a lower electrical resistivity compared with those on polyurethane and neoprene coated textiles. The potential reason for this is that any chemical reaction with the 
coating polymers during the curing process may result in increased oxidation and hence high resistivity. Also, the thermocouples on copper electrodes (TEG II) demonstrated a higher internal resistance than other samples, making metal connections unsuitable for printed TEGs application. Finally, in order to realize TEGs fully integrated into normal cotton/polyester textiles, conductive polymers with lower curing temperature (around $120^{\circ} \mathrm{C}$ or even lower) are promising potential solutions but this does require further research.

\section{REFERENCES}

[1] S. Beeby and N. White, Energy Harvesting for Autonomous Systems. Artech House, 2010.

[2] V. Leonov, "Simulation of maximum power in the wearable thermoelectric generator with a small thermopile," Microsyst. Technol., vol. 17, no. 4, pp. 495-504, Feb. 2011.

[3] T. Starner, "Human-powered wearable computing," IBM Syst. J., vol. 35 , no. 3.4, pp. 618-629, 1996.

[4] V. Misra, A. Bozkurt, B. Calhoun, T. Jackson, J. Jur, J. Lach, B. Lee, J. Muth, O. Oralkan, M. Ozturk, S. Trolier-McKinstry, D. Vashaee, D. Wentzloff, and Y. Zhu, "Flexible Technologies for Self-Powered Wearable Health and Environmental Sensing," Proc. IEEE, vol. 103, no. 4, pp. 665-681, 2015.

[5] D.-H. Kim, E. Byon, G.-H. Lee, and S. Cho, "Effect of deposition temperature on the structural and thermoelectric properties of bismuth telluride thin films grown by co-sputtering," Thin Solid Films, vol. 510, no. 1-2, pp. 148-153, Jul. 2006.

[6] W. Glatz, S. Muntwyler, and C. Hierold, "Optimization and fabrication of thick flexible polymer based micro thermoelectric generator," Sensors Actuators A Phys., vol. 132, no. 1, pp. 337-345, Nov. 2006

[7] O. Bubnova, Z. U. Khan, A. Malti, S. Braun, M. Fahlman, M. Berggren, and X. Crispin, "Optimization of the thermoelectric figure of merit in the conducting polymer

poly(3,4-ethylenedioxythiophene).," Nat. Mater., vol. 10, no. 6, pp. 429-33, Jun. 2011.

[8] Q. Jiang, C. Liu, H. Song, H. Shi, Y. Yao, J. Xu, G. Zhang, and B. $\mathrm{Lu}$, "Improved thermoelectric performance of PEDOT:PSS films prepared by polar-solvent vapor annealing method," J. Mater. Sci. Mater. Electron., vol. 24, no. 11, pp. 4240-4246, Jul. 2013.

[9] C. Navone, M. Soulier, M. Plissonnier, and a. L. Seiler, "Development of (Bi,Sb)2(Te,Se)3-Based Thermoelectric Modules by a Screen-Printing Process," J. Electron. Mater., vol. 39, no. 9, pp. 1755-1759, Apr. 2010.

[10] Z. Cao, E. Koukharenko, M. J. Tudor, R. N. Torah, and S. P. Beeby, "Screen printed flexible Bi2Te3-Sb2Te3 based thermoelectric generator," J. Phys. Conf. Ser., vol. 476, no. 1, p. 012031, Dec. 2013.

[11] a Chen, D. Madan, P. K. Wright, and J. W. Evans, "Dispenser-printed planar thick-film thermoelectric energy generators," J. Micromechanics Microengineering, vol. 21, no. 10, p. 104006 , Oct. 2011.

[12] D. Madan, A. Chen, P. K. Wright, and J. W. Evans, "Dispenser printed composite thermoelectric thick films for thermoelectric generator applications," J. Appl. Phys., vol. 109, no. 3, p. 034904, 2011.

[13] Z. Lu, M. Layani, X. Zhao, L. P. Tan, T. Sun, S. Fan, Q. Yan, S. Magdassi, and H. H. Hng, "Fabrication of Flexible Thermoelectric Thin Film Devices by Inkjet Printing," Small, vol. 10, no. 17, pp. 3551-3554, Jan. 2014.

[14] J. Kuleshova, E. Koukharenko, X. Li, N. Frety, I. S. Nandhakumar, J. Tudor, S. P. Beeby, and N. M. White, "Optimization of the electrodeposition process of high-performance bismuth antimony telluride compounds for thermoelectric applications," Langmuir, vol. 26, no. 22, pp. 16980-16985, 2010.

[15] O. Madelung, Semiconductors: Data Handbook. Berlin, Heidelberg: Springer Berlin Heidelberg, 2004.

[16] K. Yang, R. Torah, Y. Wei, S. Beeby, and J. Tudor, "Waterproof and durable screen printed silver conductive tracks on textiles," Text. Res. J., vol. 83, no. 19, pp. 2023-2031, Jul. 2013.
X. Liu, J. Zhou, Y. Yang, B. Wang, S. Member, J. Lan, C. Wang, J. Luo, W. L. Goh, S. Member, T. T. Kim, S. Member, M. Je, and S. Member, "A $457 \mathrm{nW}$ Near-Threshold Cognitive Multi-Functional ECG Processor for Long-Term Cardiac Monitoring," IEEE J. Solid-State Circuits, vol. 49, no. 11, pp. 2422-2434, 2014.

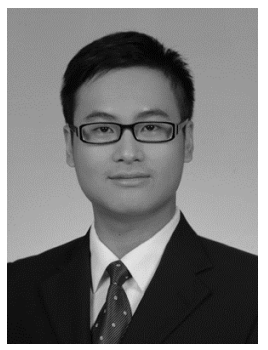

Zhuo Cao received the BSc in Material Science from Fudan University, China in 2009. He obtained his MSc and Ph.D degrees in Electronics and Electrical Engineer from University of Southampton, UK, in 2010 and 2015 respectively. He has been working as senior research assistant in Printed Electronics and Materials Lab, University of Southampton. His research interests include energy harvesting, thermoelectric, printed electronics and smart fabrics.

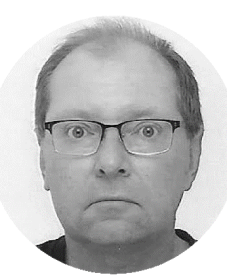

J. Tudor obtained a BSc (Eng) in electronic and electrical engineering from University College London and a $\mathrm{PhD}$ in physics from Surrey University. In 1987, John joined Schlumberger Industries working first at their Transducer Division in Farnborough and then their Research Centre in Paris, France. In 1990, he joined the University of Southampton as a lecturer. In 1994, John moved to ERA Technology becoming the microsystems program manager. In 2001, John returned to the School of Electronics and Computer Science, University of Southampton where he is currently a Principal Research Fellow. His research interests include smart fabrics, screen printing, dispenser printing, MEMS, microsystems, energy harvesting, sensors, resonant sensors, inkjet printing and wireless sensors. $\mathrm{He}$ is a co-founder of Perpetuum Ltd and a co-founder and director of two other companies Smart Fabric Inks Ltd and D4 Technology Ltd. He has 150 publications and is both a chartered physicist and engineer.

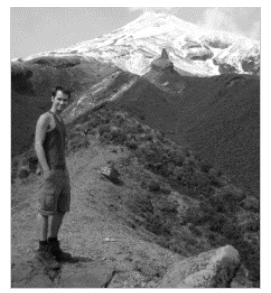

R. Torah graduated with a BEng (Honours) in Electronic Engineering in 1999 and an MSc in Instrumentation and Transducers in 2000, both from the University of Southampton. Between 2001 and 2004 Russel obtained a PhD in Electronics from the University of Southampton in the optimisation of thick-film piezo ceramics. Since 2005 he has been a full time researcher at the University of Southampton where he is currently a Senior Research Fellow. Dr Torah is a co-founder and director of the Smart Fabric Inks (in 2011) company specialising in printed smart fabrics. Dr Torah's research interests are currently focused on smart fabric development but he also has extensive knowledge of energy harvesting, sensors and transducers. He has over 50 publications in these fields.

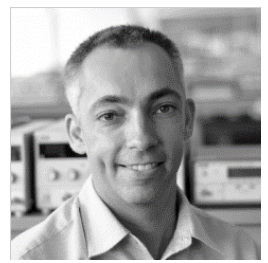

Steve $\mathbf{P}$ Beeby obtained a BEng (Honours) degree in Mechanical Engineering from the Univeristy of 
Portsmouth, UK, in 1992. He obtained his $\mathrm{PhD}$ from the University of Southampton, UK, in 1998 on the subject of MEMS resonant sensors. Following his $\mathrm{PhD}$, he became a Research Fellow in the School of Electronics and Computer Science (ECS) at the University of Southampton. He has been awarded two prestigious EPSRC Research Fellowships to investigate the combination of screen printed active materials with micromachined structures and textiles for energy harvesting. Following the first Fellowship, he became a lecturer in ECS, was appointed a Reader in 2008 and was awarded a personal Chair in 2011. His research interests include energy harvesting, e-textiles, MEMS, active printed materials development and biometrics. He leads the UK's Energy Harvesting Network and is Chair of the International Steering Committee for the PowerMEMS conference series. He is currently leading $3 \mathrm{UK}$ funded research projects and has previously been principal or co-investigator on a further 18 projects and co-ordinated 2 European Union research projects. $\mathrm{He}$ has co-authored/edited three books including 'Energy Harvesting for Autonomous Systems' (Artec House, Inc., Boston, London, 2010). He has given 14 invited talks and has over 200 publications and 10 patents. He has an H-Index of 39 with $>9000$ citations. He is a co-founder of Perpetuum Ltd, a University spin-out based upon vibration energy harvesting formed in 2004, Smart Fabric Inks Ltd and D4 Technology Ltd. 